\title{
The relationships between vaginismus and anxiety in pregnant women in Tunisia
}

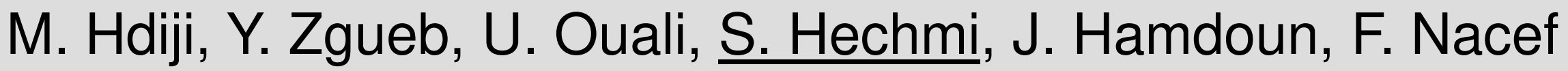 \\ Razi Hospital, "A" Psychiatric Department, La Manouba, Tunisia
}

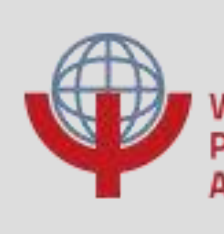

WORLD PSYCHIATRIC LISBON, 21-24 AUGUST, 2019

\section{BACKGROUND AND OBJECTIVES}

Vaginismus is a feminine sexual dysfunction that makes impossible any intercourse with penetration, but which is compatible with pregnancy. This association is delicate, pregnancy being already a period of great anxiety for the woman to which is added vaginismus. It has been already shown in the literature that anxiety is more common in women with vaginismus $[1 ; 2]$.

The aim of the study was to assess anxiety in pregnant women with vaginismus and its relationship with vaginismus in Tunisia.

\section{MATERIALS AND METHODS}

This is a descriptive, prospective and longitudinal study that has been spread over eight months, from November 2017 to June 2018, including 40 pregnant women suffering from vaginismus who consulted the emergency department of the Maternity and Neonatology Center of Tunis. The psychiatric history of these women as well as epidemiological and clinical data were collected. They were followed and evaluated by the Spielberg State Trait Inventory Anxiety (STAI) during their consultations. We used the $\mathrm{Y}$-A and $\mathrm{Y}$-B forms of the scale, which is a scale of self-evaluation of anxiety. We used a version translated into Arabic based on the French adaptation of the questionnaire [3]. This test makes it possible to compare for each subject the anxiety-state (developed at present) and the anxiety-trait constituting the personality of the subject. It makes it possible to conclude as to the anxious state or not of the subject compared to a basic state.

\section{RESULTS AND DISCUSSION}

- Nine patients (23\%) had high or very high anxiety levels. Of these nine patients, eight $(89 \%)$ had a psychiatric history. At the anxiety assessment, $82 \%$ of patients were more anxious than usual because of both vaginismus and pregnancy during consultations.

- We found a statistically significant association between anxiety and type of vaginismus. Anxiety was more often increased in women with primary vaginismus $(p<0.001)$ (see table 1$)$.

\section{REFERENCES}

[1] Watts G, Nettle D. The role of anxiety in vaginismus: a case-control study. J Sex Med. 2010;7:143-8

[2] Farnam F, Janghorbani M, Merghati-Khoei E, Raisi F. Vaginismus and its correlates in an Iranian clinical sample. Int J Impot Res. 2014;26(6):230-4.

[3] Spielberger CD, Bruchon-Schweitzer M, Paulhan I. Inventaire d'anxiété étattrait forme Y (STAI-Y). Paris: Ed. du Centre de psychologie appliquée; 1993.

\begin{tabular}{|c|c|c|c|}
\hline & Increased anxiety & $\begin{array}{r}\text { Non-increased } \\
\text { anxiety }\end{array}$ & $p$ \\
\hline $\begin{array}{l}\text { Primary } \\
\text { vaginismus }\end{array}$ & 31 (78\%) & $3(7 \%)$ & \\
\hline $\begin{array}{l}\text { Secondary } \\
\text { vaginismus }\end{array}$ & $2(5 \%)$ & $4(10 \%)$ & $<0,001$ \\
\hline
\end{tabular}

Table 1: Distribution of patients according to increased anxiety and type of vaginismus

- We did not find a statistically significant association between increased anxiety and worsening postpartum vaginismus $(p=0.15)$ despite an increase in anxiety in all women who had reported an aggravation of their vaginismus (see table 2 ).

\begin{tabular}{|c|c|c|c|}
\hline & Increased anxiety & $\begin{array}{r}\text { Non-increased } \\
\text { anxiety }\end{array}$ & $p$ \\
\hline $\begin{array}{l}\text { Aggravation of } \\
\text { vaginismus }\end{array}$ & $8(20 \%)$ & $0(0 \%)$ & \\
\hline $\begin{array}{c}\text { Non-aggravation of } \\
\text { vaginismus }\end{array}$ & 25 (62\%) & $7(18 \%)$ & 0,15 \\
\hline
\end{tabular}

Table 2: Worsening of postpartum vaginismus in patients according to increased anxiety

- Anxiety was more often increased in women with primary vaginismus. This could be explained by an underlying personality more anxious in those with primary vaginismus, and less knowledge of their bodies than those with secondary vaginismus. - In addition, we found no statistically significant association between increased anxiety and worsening post-partum vaginismus, despite increased anxiety in all women who have reported a worsening of their vaginismus. The low power of our sample may explain these findings, as worsening vaginismus should be associated with increased anxiety.

\section{CONCLUSIONS}

- Given the high prevalence of anxiety symptoms in pregnant women in general, and more particularly in women with vaginismus, it is essential that practitioners have a specific and responsive approach to managing anxiety in these patients.

- More in-depth, case-control studies of vaginismus in Tunisia may be of interest in helping mental health professionals to better manage vaginism and anxiety by adopting codified recommendations. 